\title{
O PROJETO PASTORAL DE EDIR MACEDO Uma igreja benevolente para indivíduos ambiciosos?
}

\section{Clara Mafra \\ Claudia Swatowiski Camila Sampaio}

\section{Introdução}

Este artigo analisa como uma elite cristã brasileira acabou por constituir um projeto pastoral que ganhou projeção e visibilidade internacional por seu impacto proselitista ampliado. A abordagem que estamos desenvolvendo é similar a de outros estudos atentos a referências duplas de tradição de conhecimento, da teologia e da antropologia, supondo que assim compreendamos melhor as culturas cristãs em suas particularidades, cruzamentos e choques (Robbins, 2008, p. 286).

Nesta linha de trabalho, um estudo muito bem-sucedido é The book of Jerry Falwell, de Susan Harding (2000). Ao analisar a trajetória de um único líder evangélico em suas várias dimensōes, este livro apresenta uma visão a um só tempo etnográfica e panorâmica sobre a formação da cultura

Artigo recebido em 25/10/2010

Aprovado em 28/07/2011 fundamentalista norte-americana. Inicialmente, a autora descreve como Jerry Falwell desenvolveu um modo específico de leitura da linguagem bíblica speech mimeses. No interior de uma rede de pastores, Falwell ajudou a transformar uma tradição piedosa que se autoimpunha um exílio no interior de uma sociedade abrangente marcadamente secular e trouxe esta tradição religiosa ao centro da vida pública sob o designo da "nova nação evangélica". Ao longo da leitura, observamos como o projeto pastoral de Jerry Falwell confirma o excepcionalismo norte-americano precisamente quando o projeto imperialista da nação entra em crise.

Com um aporte menos biográfico e mais socioantropológico, Simon Coleman acompanha com interesse a trajetória, a produção e a performance de Ulf Eckman, pastor sueco, fundador da World of Life Church (Coleman, 2000 e 2006). Em sua análise, Simon destaca a importância dos pastores das igrejas carismáticas e midiáticas com 
a World of Life para a constituição de um cristianismo globalizado. A exemplaridade do líder e sua família, sua intensa mobilidade nacional e internacional e a "comodificação" da palavra (em congressos, seminários, na venda de cursos, Cds, DVDs etc.) acabam transformando os próprios pastores na materialização da palavra cristã. A bíblia e a cultura escrita são relegadas ao segundo plano, e a "nova palavra” ganha uma mobilidade exponencial no mundo globalizado.

À luz desses estudos, o projeto pastoral de Edir Macedo, o fundador da igreja Universal do Reino de Deus (doravante IURD ou igreja Universal), uma das igrejas brasileiras mais bem-sucedidas em termos de proselitismo internacional, ${ }^{1}$ poderia ser uma réplica na periferia de um projeto teológico desenvolvido por elites de países centrais. De fato, alguns autores têm sugerido que Macedo tende a atualizar noções cunhadas em outro lugar, como "teologia da prosperidade", da "economia sacrificial", dos rituais de expulsão de demônios e mesmo dos escândalos e controvérsias (Campos, 1997; Mariano, 1999; Oro, Corten e Dozon, 2003; Almeida, 2009). Quando versōes folclorizadas dessa abordagem passaram a circular pela mídia, ele se tornou o exemplo extremo de "alteridade repugnante" (Harding, 1991).

Neste artigo, pretendemos ir além dessas interpretações. $\mathrm{O}$ grande triunfo e originalidade de Edir Macedo, a nosso ver, repousam em sua habilidade de transformar a "nova teologia cristã", para além de suas tendências liberais, em um projeto teológico popular. Os projetos pastorais de Falwell e Eckman funcionam perfeitamente em sociedades de economia afluente e com ethos individualista consolidado. Em países periféricos e em contextos pós-coloniais, essas teologias têm uma entrada parcial e segmentada, mas o projeto de Edir Macedo opera com sucesso justamente onde a população aprendeu a conviver com alto grau de controle social como estratégia de acesso a "bens sociais". Com efeito, esse "realismo político" vinculado ao estabelecimento de princípios de estratificação de conhecimento e poder dentro da igreja permitiram que o projeto teológico de Edir Macedo quebrasse as barreiras de difusão da "nova teologia cristâ" ${ }^{2}$ para além das fronteiras das sociedades afluentes, difundindo-a com relativa facilidade nas "periferias" do globo. ${ }^{3}$
$\mathrm{O}$ argumento aqui desenvolvido tem um caráter duplo. De um lado afirmamos que a igreja Universal apresenta um discurso moral que refuta o individualismo corrupto e narcisista, e, em seu lugar, oferece rituais que promovem empreendedores sacrificiais mesmo entre seguidores que se encontram em diferentes momentos do processo de individuação ${ }^{4}$ (Gomes, 2004; Swatowiski, 2009; Mafra, 2002). De outro lado, observamos que a elite da igreja oferece opções de acesso a "bens sociais" para seus membros sob o custo de privação do exercício de alguns "direitos individuais", isto por conta da constituiçãao estratificada da congregação no exercício de um "poder tutelar", isto é, a igreja propõe-se a administrar a liberdade de seus membros, considerando-os capazes apenas parcialmente de uma vida social plena.

Não se trata de um argumento estritamente culturalista. De nosso ponto de vista, o poder pastoral tutorial da igreja não depende da continuidade, em longo prazo, de uma cultura clientelista ${ }^{5}$ ou mandonista. ${ }^{6}$ Basta que se leve em conta um horizonte de mundo globalizado, onde as diversas populações têm a percepção de que o luxo e o conforto estão estampados na vida dos outros, reconhecendo sua dificuldade de inserção em culturas que produzem tal abundância (Robbins, 2008). A elite da igreja atua sobre tais expectativas e ansiedades, regulando o acesso a bens individuais em relação à acessibilidade de bens coletivos.

$\mathrm{O}$ artigo está dividido em três partes. $\mathrm{Na}$ primeira, indicamos algumas relaçôes de continuidade - como é usual acontecer nesse tipo de liderança carismática - entre a história pessoal de Edir Macedo e a igreja que fundou. Este tipo de articulação é esperado pelas audiências pentecostais e carismáticas e tende a pressupor um jogo de homologia entre a trajetória do líder e de sua família, a instituição e o contexto regional. $\mathrm{Na}$ segunda parte, destacamos algumas categorias nativas que ajudam a reconhecer a especificidade da ideologia semiótica ${ }^{7}$ e sua pragmática no interior da igreja, em especial, na "economia sacrificial", nas "correntes de objetos" e nas performances midiáticas. Na terceira parte, sugerimos que a riqueza da rede conceitual se torna mais evidente quando observada à luz das informações etnográficas coletadas em três países, Brasil, Portugal e Angola. 


\section{Marca e revolta}

Tal como líderes evangélicos como Jerry Falwell e Ulf Eckman, Edir Macedo construiu sua imagem apresentando sua história pessoal a partir de eventos extraordinários, ações miraculosas, que vão no decorrer da sua trajetória de vida se revelando, se articulando para engrandecê-lo. Ao tornar essa estrutura narrativa um tipo de evangelismo orientado para a mídia (Harding, 2000), a narrativa biográfica do líder religioso faz-se ambígua, sendo recebida com desdenho e descrédito ou confiança e fé. Seguidores e inimigos encontram sustentação de sua posição com sinais invertidos na mesma narrativa.

$\mathrm{Na}$ única biografia autorizada - O bispo, a história revelada de Edir Macedo, de Douglas Tavolaro (2007) -, Macedo é descrito desde o princípio como vítima de uma grande conspiração. Os três primeiros capítulos tratam de sua prisão. Era o dia 24 de maio de 1992, começo de tarde em São Paulo, quando o BMW de Edir Macedo foi cercado por vários carros da polícia civil e federal. Os agentes estavam equipados com armamento pesado, escopetas, metralhadoras e revólveres. Dentro do carro estava o bispo, sua esposa Ester, a filha Viviane e uma amiga da filha, que retornavam de um culto na IURD de Santo Amaro. Ao ouvir a voz de prisão, Edir saiu do carro com as mãos para o alto. Não reagiu, nem ofereceu qualquer tipo de resistência. Em seguida, o bispo foi colocado em um camburão e conduzido para a delegacia da Vila Leopoldina, onde permaneceu encarcerado por onze dias. Relembrando a cena diante das câmaras vinte anos depois, Edir Macedo conta que "foi como um ataque cardíaco. De repente, o terror. Comecei a viver um pedaço do inferno" (Idem, p. 20). O juiz que expediu o mandato de prisão se fundamentou em acusações de charlatanismo, curandeirismo e estelionato. Por 500 mil dólares a igreja contratou um dos melhores advogados do país, Márcio Thomaz Bastos, que o retirou da prisão onze dias depois com um pedido de habeas corpus. Para Macedo, o episódio "Foi uma grande lição de vida, [aprendi a] transformar as adversidades... como se diz, fazer do limão, uma limonada" (Idem, p. 24).

A prisão ocorreu em meio ao processo de compra da Rede Record pela igreja de Edir Macedo.
Foi uma luta de titãs, com um circuito de capital que adentrava os milhões de dólares. $\mathrm{O}$ ato de prisão ocorreu em momento crucial dessa transação, quando parte do valor já tinha sido pago aos proprietários anteriores, mas a concessão federal ainda não tinha sido expedida. $\mathrm{O}$ caráter marcadamente político da decisão de concessão - que deve ser sancionada pelo presidente da República - permitiu açôes mais ousadas das pessoas "incomodadas" com a negociação, boa parte, membros da elite política e de empresários da mídia. Com este enquadramento, para o fiel da igreja, o evento é signo de justiça divina: não porque com a prisão se reparam faltas de um cidadão diante da lei, - como quer o "inimigo" do bispo -, mas porque ali se criou um mártir.

Em suas memórias, Edir Macedo lembra que passou por aquela situação com amargura e sobriedade. Não é o caso aqui de explorar as várias dimensóes da narrativa construída por Edir Macedo, mas é importante chamar atenção para sua estrutura, algo que está presente em sermôes, prédicas, reportagens, site de Edir Macedo, autobiografia autorizada, fala de muitos de seus seguidores, e que remete à tradição judaico-cristã de que "os humilhados serão exaltados" (Lucas, 18.14).

Para o ouvinte com "boa fé", o evento do aprisionamento tendeu a ser descrito do ponto de vista da vítima injustamente acusada. Não é fortuito, portanto, que a fotografia com a imagem de Edir Macedo sentado em um banco na cela atrás das grades lendo a Bíblia tenha se tornado o ícone do representante máximo da igreja Universal do Reino de Deus. Desde então, a fotografia tem sido sistematicamente reproduzida pela imprensa da igreja Universal em reportagens e documentários sobre Edir Macedo, no jornal Folha Universal, em panfletos ocasionais, na capa da biografia do bispo. A leitura feita a partir dessa imagem é de que o bispo conheceu a humilhação por dentro, e por isso mesmo sabe compartilhar sua fé com pessoas que a experimentam cotidianamente.

Mais que um evento fortuito, a humilhação é moto contínuo na biografia do bispo. Edir Macedo nasceu com um problema congênito - seus indicadores e polegares são deformados e tem movimentos restritos - estigma que foi interiorizado pelo bispo ainda na infância: "Eu era o patinho feio. Eu 
tinha a sensação de tudo que eu fazia daria errado: uma pipa rasgada, balōes que pegam fogo. Às vezes eu me sentia como um transtorno" (Tavolaro, 2007 , p. 59). Com o estigma de alguma forma controlado, ele se tornou um jovem confiante, vivaz e belo, que conquistou a "mulher de seus sonhos", Ester, sua esposa. Entretanto, sua primeira filha, Viviana, veio a nascer com uma fissura labiopalatal - a marca do menino tinha sido geneticamente transmitida para a nova geração:

[...] levei um tremendo susto. A menina era um horror. Eu disse para mim mesmo: 'Meu Deus, eu não quero esse monstrinho'! Sua fisionomia era terrível. Eu imaginava o sofrimento que seria o crescimento daquela criança. Eu sabia o que era ser defeituoso. Imagina ela, então, menina, certamente vaidosa... Não, não queria. Preferia sua morte (Idem, p. 96).

Nessa passagem, nada da contrição e da convencionalidade burguesa que apara e adoça lembranças. Edir Macedo fixa-se na violência do evento, de que ele tinha gerado um rebento deformado, um ser que teria, dali para frente, uma trajetória trágica em função de uma marca que não pediu e que não poderia ficar oculta. A reação do pai foi bruta como é bruto mundo em que Macedo vive: "Eu não quero este monstrinho!".

Eu e Ester choramos muito. Foi doloroso. Em meio ao choro, manifestei minha revolta $\mathrm{e}$ decepção. Ajoelhei na cama para orar e, num acesso de raiva, soquei a cama várias vezes. Determinei que, a partir daquele momento, eu iria deixar minha igreja [naquela época, a Nova Vida] e ajudar as pessoas sofridas como eu (Idem, p. 97).

Edir Macedo faz do nascimento trágico da filha o ato inaugural da nova igreja. Explicitamente, ele afirma que sua mensagem será dirigida para pessoas que conheceram uma grande restrição de liberdade; consideradas incapazes, excluídas do destino redentor prometido pelo sonho moderno.

$\mathrm{Na}$ nova igreja, o bispo pedirá que as pessoas se revoltem, saboreiem a raiva do reconhecimento de sua própria situação e desafiem a Deus "determinando" um destino alternativo. Com a revolta, o sabor da raiva e o imperativo no trato com o divino, a "confissão positiva" proposta por Ulf Ekman ganha uma tradução acessível às populações que experimentam a modernidade ${ }^{8}$ como privação.

\section{Comunidade estratificada}

Uma das peculiaridades da IURD em relação ao universo pentecostal e carismático está no fato de esta igreja não recusar uma membresia flutuante. Ao contrário do modelo congregacional cristão clássico - que conta com o princípio da conversão, abandono dos referentes de sociabilidade anteriores e reconstrução dos laços de pertencimento a partir de um novo universo valorativo e simbólico (Hefner, 1993) -, a IURD parece não apenas conviver, mas usufruir de uma adesão comunitária frouxa. Em função dessa característica, alguns autores a classificam como igreja de "serviço" (Campos, 1997; Mariano, 1999), postulando que essa instituição não se preocupa em operar a "reforma" subjetiva de seus membros em função de uma agência hipertrofiada da instituição como coletivo em um "mercado religioso" plural.

Porém, uma comunidade formada apenas por frequentadores que buscam "serviço religioso" é bem diferente da formação de uma eklesia estratificada, que convive pacificamente tanto com frequentadores esporádicos como com membros assíduos. Trata-se de uma estruturação congregacional que gera tensōes e dificuldades, e isto tem relação com a constituição de um "poder tutelar".

Edlaine Gomes (2004) chamou atenção para a estratificação congregacional da IURD, e sua pesquisa localizou quatro tipos ideais de frequentadores, ordenados hierarquicamente. Primeiro, os membros convertidos, os obreiros, os pastores e os bispos, todos denominados vernacularmente como "servos de Deus". Estes formam o "clero" da igreja. São pessoas que passaram pelo "batismo das águas" e do Espírito Santo, e assumem a identidade iurdiana. Em seguida, "os membros em processo de conversão", frequentadores ainda não batizados pelo Espírito Santo. Terceiro, os membros esporádicos, 
aqueles que procuram a igreja em busca de uma bênção imediata. Por fim, as pessoas "do mundo" ou o horizonte aberto de difusão e influência da mensagem iurdiana (Gomes, 2004, pp. 123-124).

É a terceira categoria, os esporádicos, que trouxe para a teologia da IURD uma linguagem $p o p$ do mundo evangélico em diferentes naçôes. Jargões, temas, motes que aparecem nos sermôes e campanhas da igreja são transferidos para a linguagem das ruas, sem o compromisso da coerência e da ratio especificamente cristã. Quanto mais o membro se engaja na vida institucional, mais sua vida privada se parece com a de outros pentecostais clássicos e, como eles, é capaz de expressar retoricamente os motivos de sua adesão religiosa. Porém, distintamente dos outros pentecostais brasileiros, os iurdianos podem ser praticantes e não praticantes (Campos, 1997; Freston, 2008). ${ }^{?}$

Como é possível que um conjunto de participantes esporádicos retorne ocasionalmente a IURD sem aderir à ideia da "reforma da pessoa", como supõe a conversão tradicional, e sem se sentir enganado ou frustrado? Se esses frequentadores não tem a adesão suficiente para compartilhar o carisma institucional, numa constituição de vínculo por participação comunitária superficial, o que os move no retorno à igreja?

Para avançar reflexivamente sem cair em um pressuposto universalista e invariante do frequentador como um mero "consumidor religioso", optamos por adensar nossa compreensão da mensagem proselitista da igreja Universal em seus próprios termos. Se a audiência da IURD é estratificada, sua mensagem deve ser, de algum modo, atraente tanto para frequentadores de "primeira visita" como para nascidos e criados na igreja.

A chamada clássica da Universal é "Pare de sofrer". Este mote, junto com a imagem de um rapaz pensativo, estão inscritos na fachada de boa parte dos endereços da igreja Universal pelo mundo. Em seu discurso de comemoração dos 25 anos da igreja e de inauguração da majestosa catedral da igreja em Del Castilho (onde a igreja nasceu), o bispo Macedo fez a seguinte oração.

Espírito Santo, eu te peço. Eu suplico. Plante no coração de cada uma dessas pessoas a semente da revolta. A revolta. A ira. Espírito, pōe revolta dentro destes corações para não aceitar essa situação desgraçada, decadente, mesquinha, em que ele(a) está vivendo (Gomes, 2004, p. 101).

Para se compreender essa passagem, é importante fazer um recuo, lembrando que o líder da IURD frequentemente utiliza um tom didático em seus sermões, dirigindo-se em tom assertivo a um público "ignorante na fé". Segundo Dilley (2010), a tradição cristã em seu longo percurso proselitista deu origem a diferentes significados da palavra "ignorância", todos com um subtexto moral: primeiro, ignorância é sinônimo de "inocência", pessoa pura e moralmente louvável. Um segundo sentido é de ignorância como "falta de conhecimento" ou "inexperiência", como a pessoa que está inconsciente de sua situação, mas que procura, tão logo tome consciência, superá-la. Terceiro, o mais grave moralmente, envolve a ignorância como "recusa a conhecer", a pessoa que intencionalmente procura não tomar conhecimento de alguma coisa. Muito frequentemente, missionários euro-americanos tendem a oscilar entre dois extremos, atribuindo ora inocência e louvor ora ignorância intencional e pecado mortal aos neófitos. Na IURD, os pastores aprendem a sobrepor os três sentidos de ignorância em um único: como "falta de conhecimento" ou "inexperiência". Sem a expectativa de encontrar interlocutores "inocentes", os pastores dessa igreja dedicam-se a comunicar ostensivamente chaves de acesso a um "Deus que funciona" para pessoas "ignorantes da fé" (Tavolaro, 2007, p. 132).

No vernáculo da igreja, o iurdiano deve buscar insistentemente "a fé ativa", ou seja, deve propor objetivos de mudança de sua vida, pedir para Deus a mudança, e sacrificar-se. Segundo o bispo Macedo, ao exercitar a reciprocidade com o Divino, os homens e as mulheres aprenderão a se conhecer, superando sua alienação.

Você vai aprender quem você é a partir do momento que você é levado ao sacrifício. Você vai se conhecer, ou conhecer as suas forças, se você for levado ao sacrifício. Só vai conhecer a si próprio, a sua fé, seu relacionamento com Deus, quando você for levado a uma situação 
que vai requerer de você a expressão daquilo que está dentro de você [...] justamente naquele momento de profunda angústia e aflição, você vai manifestar seu verdadeiro caráter, a sua verdadeira fé (Gomes, 2004, p. 105).

A "economia sacrificial" faz parte do ethos evangélico carismático e pentecostal contemporâneo. Ainda na década de 1980, um evangelista televisivo como Jerry Falwell conseguiu triplicar o volume de doaçôes de sua audiência em uma semana ao construir uma narrativa aberta e interativa com um resultado final específico - a compra do terreno para construir uma universidade evangélica - no enfrentamento do mundo secular. Sua performance como apóstolo permitia a participação ativa, naquela semana, de sua audiência na batalha espiritual, em uma etapa decisiva do enfrentamento das forças do bem contra o mal, em uma disputa que afeta o cosmos (Harding, 2000, pp. 105-125). Mais sistemático e menos performático, Ulf Ekman, líder religioso do Word of Life, analisou e sistematizou os elementos da economia sacrificial aprimorando a noção de "confissão positiva", que pressupõe, segundo Coleman, que "palavras tenham qualidades de objeto, ou seja, elas poderiam ser removidas ou retidas pelas pessoas com existência semiautônoma" (2006, p. 173). Essa versão do cristianismo - que Ulf Ekman se orgulha em disseminar em suas escolas bíblicas - tende a aproximar palavra cristã e dinheiro, algo que causa repulsa em tradições cristãs mais estabelecidas, cujo desenvolvimento histórico está atrelado ao processo inverso, de separação entre dinheiro e transcendência.

Edir Macedo, por sua vez, transportou boa parte dos pressupostos teológicos da "economia sacrificial" já conhecidos e elaborados por outros teólogos em uma "economia sacrificial ritual". Pode-se dizer que bispo Macedo construiu a versão mais "católica” de uma elaboração teológica de raiz reformada. Para compreender a importância desta pequena diferença, é preciso compreender como a "economia sacrificial ritual" da Universal está atrelada a uma distribuição estratificada. No topo da hierarquia encontra-se o clero - aqueles que conhecem os segredos da produção ritual. $\mathrm{Na}$ base, uma congregação heterogênea, que engloba indiferentemente desde o mais ávido frequentador ao visitante curioso esporádico. Com o alargamento do público participante da vida ritual da igreja e a extensão da benção do Deus cristão para convertidos, esporádicos e curiosos, Edir Macedo torna acessível a economia sacrificial para uma audiência extensa e que muitas vezes ignora os parâmetros do ethos evangélico.

Dificilmente alguém sai das reuniōes da igreja Universal sem carregar algum pequeno objeto, uma miniatura - segundo o vernáculo dos especialistas religiosos iurdianos, estes são os "pontos de contato" como sal grosso, rosa ungida, água fluidificada, fitas e pulseiras, ramo de arruda (Campos, 1997; Gomes, 2004; Kramer, 2001). Segundo o Estatuto da IURD, o clero da igreja é levado a utilizar "objetos" em função do problema de "falta de conhecimento" de sua audiência. Pessoas "maduras na fé" conseguem entender que "o poder está no Senhor Jesus Cristo e na ação do Espírito Santo", e essas pessoas conseguem acessar o cristianismo em sua total potencialidade, como uma religiosidade de abstração. No entanto, "pessoas imaturas na fé”, implicitamente, aquelas que mais precisam conhecer a mensagem cristã, são as que precisam de "pontos de contato". O estatuto continua:

[...] nem todas as pessoas necessitam de "pontos de contato" para despertarem fé suficiente, mas a maioria precisa, razão pela qual realizamos nas reuniōes as correntes e distribuímos gratuitamente coisas ligadas à Palavra de Deus direta ou indiretamente, literal ou simbolicamente, para trazer às pessoas uma confiança, pelo menos um fio de esperança, de fé, e assim levá-las a serem abençoadas (Estatuto, s/d, pp. 66-67).

Além disso, nos cultos da Universal é muito comum assistir a encenações como a que segue, descrita por Mafra (2002) em sua pesquisa de campo, na IURD de Botafogo, no Rio de Janeiro:

No púlpito, enquanto relê a passagem bíblica João 10:9, - "Eu sou a porta. Se alguém entrar por mim, será salvo, entrará, e sairá, e achará pastagem"-, o pastor passa pelo portal. Em seguida, ele se coloca novamente diante do portal. Simula que quer passar, mas vai 
pelo lado. Caminhando pela lateral do portal, o pastor se agacha e se movimenta sorrateiramente. Age como um ladrão. Daí se volta para o público e pergunta, "esta pessoa passou pela porta?”. Prontamente, o público responde que "Nnãããããõooo". Retorna e com o corpo ereto e cabeça erguida, entra pelo interior do portal. "Assim é que se passa pela porta da fé", explica.

Nas reuniões da IURD, problemas altamente abstratos da teologia cristã são remetidos a exercícios simples com objetos e simulações. Diante desses objetos, os pastores apresentam algumas alternativas de ação - um portal que pode ser transposto pelo centro ou pela periferia, um muro que pode ser escalado, circundado ou destruído etc. As alternativas não são apenas mencionadas, mas acompanhadas de atuações do pastor, em que não só as palavras, mas a expressão corporal é significativa - um corpo que passa agachado e sorrateiro, moralmente condenável, um corpo altivo e com movimento decidido, moralmente louvável. O desenvolvimento de encenaçôes é indicativo de que os pastores da IURD estão atentos à produção de uma didática que supõe que corpo, mente e ambiente se informam e constrangem reciprocamente na construção do conhecimento.

Essas técnicas, do "ponto de contato" e do "conhecimento encorporado", pressupōem a existência de uma grande distância entre audiência e clero, entre quem ensina e quem aprende. Elas estão a serviço de um proselitismo de teor paternalista, que recusa a tradição reformada da democratização do conhecimento cristão, cujo ideal é que cada irmão seja um pastor.

Em síntese, uma das diferenças do projeto pastoral de Edir Macedo sobre os de Jerry Falwell e Ulf Ekman é abrir as portas do cristianismo para uma audiência ampliada e heterogênea. Para dar conta disso, a igreja de Edir Macedo acaba por se organizar segundo uma hierarquia com posições de autoridade bem definidas.

O que escapa a essa linha analítica é o fundamento da formação do consenso no interior de uma instituição tão claramente autoritária. Como o mesmo público que aprende a se "revoltar" com sua condição de vida, que está frequentemente se auto- questionando sobre desejos realizados e alcançados, que expressa de modo claro suas críticas às autoridades constituídas, que tem sua atenção dirigida às falhas e às corrupções de instituiçōes e projetos concorrentes, aceitaria, no interior da IURD, submeter-se pacificamente a uma autoridade incondicional? Como essa tensa composição de "revolta" e "submissão" não corrói o projeto pastoral de Edir Macedo a partir de dentro?

As etnografias desenvolvidas em Brasil, Portugal e Angola mostram que o cálculo de reciprocidade da tensão revolta/submissão não se realiza em termos estritamente individuais. Sem a mediação agressiva da Universal no espaço público em contextos pós-coloniais, no espaço de mercado, de mídia, da política, a "modernidade" seguiria acessível apenas para poucos e inacessível para muitos. Em outras palavras e adiantando uma hipótese genérica que deve ser avaliada futuramente, em situaçóes de "periferia" do sistema de mercado mundial, é interessante que a instituição religiosa que se proponha a operar "reformas" da pessoa ofereça, além de um leque instrumental de apoio para a reforma da subjetividade, também seja ela própria uma instituição polivalente, capaz de fazer frente ao monopólio das elites estabelecidas regionalmente, criando assim acessos alternativos ao "moderno".

\section{Brasil}

Era o ano de 1977 e o Brasil vivia sob regime de exceção, com o comando de um presidente militar, general Ernesto Geisel, quando três pastores, Edir Macedo, Romildo Ribeiro Soares e Roberto Augusto Lopes, fundaram a igreja Universal do Reino de Deus.

Ao fundar a nova igreja, Edir Macedo rompeu definitivamente com a igreja Nova Vida, instituição que o formou como pastor e que foi precursora da Teologia da Prosperidade no Brasil. O projeto pastoral de Mac Alister, missionário canadense que dirigia a Nova Vida, estava claramente voltado para as camadas médias urbanas. Ele divulgava a teologia da confissão positiva e de recusa do fracasso para uma audiência com recursos adequados para a entrada em um mercado de trabalho competitivo. 
Nessas camadas sociais, ressoava bem um projeto pastoral de empreendedorismo com conformismo social. Porém, segundo Campos (1997) e Mariano (1999), desde o início o foco do projeto pastoral de Edir Macedo foi as camadas populares, em uma composição ousada de empreendedorismo, revolta e inquietude. Além disso, a alternativa pastoral de Edir Macedo é distinta do projeto católico, especialmente porque este opera com uma noção de popular como tradicional ou de raiz rural. Neste registro, como bem afirmou Patrícia Birman, o popular está associado ao localismo: "[no catolicismo] as representaçôes do popular promovem uma imagem 'limpa' de uma ordem simbólica em que elementos aparentemente díspares se encontram relacionados por traços de união provenientes de um território embebido em tradicionalidade" (2003, p. 242).

Para o clero católico brasileiro (muitas vezes composto por estrangeiros), as camadas populares aproximam-se da alteridade "pura" e "inocente". Em contrapartida, Edir Macedo concebe o "popular" como aquele que busca os signos de riqueza, opulência, cosmopolitismo e globalização. A IURD dirige-se a essa audiência apresentando-se como $o$ canal social que garante de maneira eficiente $o$ acesso e a distribuição dos signos de modernidade "a quem quer que a procure". Não se imputa uma relação de oposiçãao entre "ser popular" e "modernidade", nem se atribui, ao popular, um lugar social de inferioridade do ponto de vista simbólico. Com essa solução pastoral, Edir Macedo conseguiu furar o cerco da hegemonia católica, conquistando o maior crescimento da membresia em todos os tempos da história nacional. ${ }^{10}$

Dados etnográficos ajudam a compreender melhor a importância, neste projeto pastoral, de se adquirir e acumular capital econômico e político no sentido de criar alternativas de atualização da "mensagem de prosperidade" para populações previamente excluídas do mercado. Ou seja, no esforço de aproximação entre "modernidade" e localidade, além do aparato da mídia da Universal, são fundamentais as mediaçôes institucionais localmente situadas. Os dados a seguir foram coletados por Cláudia Swatowiski em sua pesquisa de campo, entre 2005 e 2006, na cidade litorânea de Macaé, situada no norte do estado do Rio de Janeiro (Swatowiski, 2009).
Desde 1974, em função da descoberta de petróleo na Bacia de Campos, Macaé, a antiga "princesinha do Atlântico", viu-se catapultada para o centro de uma dinâmica econômica, cultural e política de abrangência internacional. Com a instalação da base da Petrobrás em suas praias, não só a paisagem urbana sofreu ampla reformulação. Entre 1980 e 2001 população da cidade passou de 59 mil habitantes para mais de 120 mil (censo 1980 e 2001). Profissionais altamente qualificados, vindos de diferentes lugares do Brasil e do exterior formaram a nova elite da cidade, sobrepondo-se à elite tradicional. Ao mesmo tempo, muitos migrantes com pouca qualificação chegaram a Macaé em busca de emprego, atraídos pelas notícias que circulavam na grande mídia. As oportunidades eram muitas, mas não para todos, e a população local se viu pressionada por um mercado de trabalho competitivo e exigente. As periferias pobres cresceram significativamente, sinalizando a dificuldade de acesso a recursos da modernidade para boa parte da renovada população.

A igreja Universal instalou-se em Macaé em 1993, mas só veio a inaugurar sede própria em 2002. O Templo Maior, com capacidade para mais de 1.200 pessoas, foi construído com recursos da própria instituição e ganhou destaque na imprensa local, como um indício da prosperidade da cidade e de sua "modernização". Além disso, a igreja marcou presença entre os habitantes da cidade ao oferecer concepções cosmológicas e mecanismos rituais que capacitavam os indivíduos a prosperarem por si próprios, incentivando o "empreendedorismo" e o trabalho autônomo. Porém, distintamente da Petrobrás, que tendia a descartar os trabalhadores "pouco qualificados", a IURD incentivava sua audiência a buscar alternativas de empreendedorismo não "tão de ponta", para suprir demandas por serviços e comércio nas franjas da indústria petrolífera. Assim, incentivou-se a formação de redes de sociabilidade entre os frequentadores do Templo Maior por intermédio das quais iurdianos de diferentes estratos sociais eram encorajados a constituir pequenas empresas e iniciativas de serviço e comércio.

Ao mesmo tempo, o discurso de empreendedorismo da IURD estabelecia mediações com concepçōes anteriores. Um bom exemplo é o de João, 
fiel da IURD que conseguiu emprego em uma plataforma de petróleo, mas que, diante da impossibilidade de conciliar vida profissional e a manutenção de laços de família, optou por abandonar o emprego. No caso, o empreendedorismo iurdiano com ênfase no trabalhador sacrificial se impôs sem sobrepor o valor do "dinheiro" sobre o valor cristão da família (Swatowiski, 2009).

Ainda que breves, essas referências etnográficas corroboram a percepção de que em um país como o Brasil a "modernidade" chega ou via a antiga elite católica, - em geral, conformada com o padrão de desigualdade instituído -, ou via empreendedores internacionais e nova elite - em geral, atores socialmente desatentos aos excluídos do lugar. Diante dessa redoma de poder econômico, político e cultural, quando se busca a redistribuição das benesses do capitalismo liberal de modo que os bens sociais sejam acessíveis a uma população de baixa qualificação, é importante contar, em nome de Deus, com uma instituição religiosa que também se constituía como um conglomerado empresarial e uma força política relevante. Em outras palavras, o projeto pastoral de Edir Macedo parece levar em conta que, para que a teologia da prosperidade ganhe sustentabilidade em países de desenvolvimento tardio, há que se "furar", com certa agressividade, os constrangimentos regionais de acesso ao moderno.

\section{Portugal}

A IURD chegou a Portugal em 1989. Inicialmente, diante da forte tradição católica com privilégios no interior do Estado (garantidos pela Concordata de 1940, reformulada em 2004), a IURD encontrou grande resistência. Para piorar a situação, de início adotou uma estratégia proselitista agressiva (Mafra, 2002), fato que resultou em uma mobilização social de crítica e rejeição "àquela igreja brasileira". Ainda assim, a Universal conseguiu atrair um número significativo de pessoas em Portugal, sendo a grande maioria de imigrantes. ${ }^{11}$

$\mathrm{O}$ momento era de crescimento econômico por conta da entrada do país na União Europeia em 1986. Com isso, o fluxo de imigrantes aumentou significativamente - inicialmente vinham das ex- -colônias portuguesas e posteriormente da Ásia e de países do Leste Europeu (Malheiros, 1996). Portugueses que viviam no exterior também começaram a retornar à terra natal, atraídos pelas novas perspectivas. Depois de um longo período de "atraso" (forma como se referem os portugueses à época do Estado $\mathrm{Novo}^{12}$ ), Portugal entrou em um processo de abertura gradual.

Nos primeiros anos de União Europeia, Portugal, país periférico no contexto europeu, buscou recuperar o "tempo perdido". A facilidade de crédito, de acesso a bens de consumo, de circulação pelos países vizinhos e de fluxo de informaçôes gerou euforia entre os portugueses, mas as possibilidades de acesso a esta nova realidade não eram iguais para todos. Passado o entusiasmo de um período de grandes investimentos internacionais, muitos obstáculos começaram a aparecer. Atualmente, na mídia, fala-se exaustivamente sobre a dificuldade dos portugueses de honrar dívidas, da falta de empregos e da situação delicada da população envelhecida. ${ }^{13}$ Jovens bem qualificados saem do país, atraídos por boas oportunidades em outros países da Europa. Os imigrantes, que geralmente ocupam empregos de menor qualificação, submetem-se a condições desfavoráveis de trabalho.

Neste contexto a Universal procura criar interlocução com um público que enfrenta "privação". Em campanhas ${ }^{14}$ realizadas pela IURD em Portugal, a revolta, cuja manifestação é incentivada como reconhecimento de uma condição indesejada, ganha conotação de justiça e luto. Por exemplo, em outubro de 2008, a igreja realizou uma campanha nacional na qual obreiros se vestiam de preto e pastores e bispos reclamavam por justiça. Lembravam da citação bíblica "bem aventurados os que têm fome e sede de justiça, porque serão fartos" (Mateus 5:6). A indignação poderia ter os mais variados motivos: desemprego, subemprego, doença, pobreza, problemas sentimentais e de família. O culto tornava-se o espaço para reivindicar direitos diante de Deus. Não apenas era preciso declarar sua insatisfação, como também marcar o luto ${ }^{15}$ por tudo que se vivia, sinalizando que aquele pretendia ser um rito de passagem para uma nova condição.

Durante as reuniōes, pastores e bispos estabeleciam um paralelo entre a luta por justiça a ser 
praticada por cada fiel e aquela vivida institucionalmente. A campanha foi realizada no momento em que a IURD iniciava a construção do Centro de Ajuda Espiritual no Porto. A instituição arrecadava recursos para viabilizar as obras, e expressava, como slogan publicitário, sua luta: "não é justo pararmos no meio do caminho".

O Centro de Ajuda Espiritual do Porto pode ser considerado a materialização de uma nova apresentação pública da IURD em Portugal. Seu projeto arquitetônico revela um distanciamento do imaginário religioso tradicional e uma aproximação com referenciais modernos e laicos. Isto significa que, depois de enfrentar forte resistência da sociedade portuguesa à sua atividade, a igreja, desde 1997, optou por rever sua postura no espaço público. Deixou de lado a lógica agonística, o discurso persecutório e o confronto declarado com a igreja Católica, para adotar uma postura de competitividade, aproximando-se de referenciais hegemônicos e "modernos". Em busca de legitimidade e de um novo lugar social no contexto português, a IURD reformulou o conteúdo e a programação visual de suas mídias, ${ }^{16}$ adotando novos nomes para as reunióes da rotina semanal e para seus lugares de culto.

\section{Angola}

O primeiro avanço do projeto missionário da Universal na África aconteceu em 1991, com a instalação da igreja em Angola. Mesmo com as guerras civis, a Universal tem investido no país, e desde 1998 conta com a retransmissão do sinal da Rede Record de televisão (Fonseca 2003) e com uma presença marcante de rádios AMs e FMs. A Universal também investiu em uma rede de templos extensa. Com o fim das guerras, sua expansão foi facilitada e, em 2004, os líderes da igreja vieram a público anunciar que tinham chegado a todas as dezoito províncias angolanas, com uma rede nacional de 124 templos (Freston, 2005).

Angola é um país que acumula uma longa história de guerras. Entre 1961 e 1974, o povo angolano lutou pela independência política de Portugal, que, sob o regime autoritário do Estado Novo, mantinha Angola, Moçambique, Guiné-Bissau e
Cabo Verde como colônias no continente africano. O período foi marcado pelo surgimento de diferentes frentes políticas organizadas e militarizadas. Em 1975, o Movimento Popular pela Libertação de Angola (MPLA), conquistou a independência e estabeleceu um regime político inspirado no marxismo-leninismo. Porém, a vitória do MPLA não foi consensual, tornando-se motivo para outro longo período de guerras, de 1975 a 1991. Entre 1992 1994 e 1998-2002 as guerras civis continuaram, em cisões promovidas tanto por disputas políticas como por questões econômicas.

As guerras tiveram efeitos devastadores em todo país. Atualmente, os sistemas de abastecimento de água, eletricidade, saneamento básico e ensino são precários e circunscritos a poucas regiōes. Ao longo das últimas décadas ocorreu uma intensa migração de áreas rurais, inicialmente mais afetadas pelas guerras, para a já saturada capital Luanda, que concentra atualmente cerca de $1 / 3$ da população do país (com aproximadamente 4 milhôes de habitantes).

Desde o fim das guerras, em 2002, o governo angolano concentra esforços para um projeto de reconstrução nacional, solicitando a colaboração em especial de grupos e instituiçôes religiosas. ${ }^{17}$ As religiōes são reconhecidas como estruturas institucionais voluntárias, com ramificações sociais importantes, e que poderiam cooperar em açôes assistenciais e humanitárias. Por isso não é estranho que a IURD ganhe destaque neste cenário nacional justamente por seu "braço de ação social".

Em pesquisa realizada no site da Agência de Notícias Oficial de Angola, Angop, entre as 174 notícias sobre ações sociais desenvolvidas no país de 2001 a 2010, cem referem-se a ações assistenciais e serviços civis prestados pela igreja Universal. $\mathrm{Na}$ lista de ajudas prestadas às populações pela igreja, consta serviços de alfabetização, doação de alimentos, de sangue, incentivo à votação, serviço civil, ajuda a idosos e até mesmo a doação de trombetas para a recepção de um evento esportivo continental. A atuação da IURD em projetos sociais está tão bem estabelecida que até mesmo autoridades governamentais podem reivindicar uma atuação cívica para a igreja. Este foi o caso da governadora de Luanda, Francisca do Espírito Santo que, em visita a Catedral da Fé em Luanda, sugeriu que a igreja 
abrisse um centro de formação profissional, realizasse registro de nascimento e a emissão de carteira de identidade. $\mathrm{Na}$ mesma ocasiāo, ela aproveitou a oportunidade para agradecer, pois "a palavra da igreja tem ajudado os angolanos na pacificação dos espíritos, não apenas dos conflitos familiares, mas também nos sociais". ${ }^{18}$

Desde seus primórdios, a IURD articulou assistência social com estratégias expansionistas (Machado, 2003). No Brasil, o assistencialismo institucional da IURD via $\mathrm{ABC}^{19}$ tornou-se tão eficaz que passou a afetar as redes tradicionais de clientelismo, do tipo patrão-cliente, ponto de apoio do poder político tradicional no país. Neste novo assistencialismo, explica Machado, a IURD passou a funcionar como uma força centrípeta de poder, pois novos atores políticos encontraram na estrutura eclesiástica um modo de se projetar e, em contrapartida, ao serem bem-sucedidos nos processos eleitorais, esses políticos garantem a ampliação de influência da igreja na política e no espaço público (Oro et al., 2003; Birman, 2006; Burity e Machado, 2005).

Em Angola, não temos dados suficientes para afirmar que a IURD segue o mesmo artifício de retroalimentação circular assistencialismo institucional e poder. Porém, se nos apoiarmos nas notícias da Angop, é evidente que a Universal já se afirmou naquele país como uma instituição pública "doadora de bens sociais". Além disso, como se trata de um país em processo de constituição de uma "comunidade imaginária”, onde questôes relativas à pobreza, à fragmentação social, à multiplicidade linguística e cultural são discutidas e disputadas, o projeto institucional de Edir Macedo tende a aparecer como ideal para alguns segmentos sociais. À primeira vista, esse projeto parece suprir as demandas por modernidade das populaçôes locais, assim como responde às expectativas paternalistas das antigas e novas elites via açôes centralizadas e autoritárias.

\section{Considerações finais}

Assim como os pastores Jerry Falwell e Ulf Ekman, Edir Macedo tem uma percepção aguda das forças que regem o mercado. Tornou-se célebre sua afirmação de que "assim como o sangue está para o corpo humano, também o dinheiro está para a obra de Deus". Neste artigo, procuramos destacar como esta atenção ao mercado em países com entrada tardia na economia capitalista mais competitiva levou Edir Macedo a incluir em seu projeto pastoral a projeção de uma instituição centralizada e autoritária. Também argumentamos que a IURD é a extensão de um líder que deseja que a mensagem de cristianismo liberal seja acessível para populaçôes parcamente qualificadas em um o mercado de trabalho competitivo e situadas em contextos nacionais relativamente periféricos na composição do sistema capitalista global.

Com base nas etnografias, foi possível constatar que a igreja Universal demonstra "generosidade" de dois modos. Primeiro, formula campanhas que respondem a especificidades individuais; segundo, autoidentifica-se no espaço público como uma instituição que contribui para o bem coletivo. Os templos e as catedrais são os primeiros indicadores desse tipo de ação: seus prédios são grandiosos, luxuosos e confortáveis, desenhados como espaços seguros e multifuncionais (Gomes, 2004; Mafra e Swatowiski, 2008). São geralmente construídos em áreas urbanas decadentes e superpopulosas, criando um contraste que amplifica a percepção de luxo e conforto. Além disso, a igreja se autoidentifica como um conglomerado empresarial, cujas atividades de mídia (televisão, internet, rádio e gráfica) lhe permitem um funcionamento autônomo e independente em uma rede globalizada. Atualmente, a Universal é uma das poucas igrejas cristãs com capacidade de produzir um circuito de mídia com "progressivas conexôes entre atividades rituais 'locais' e outras que saem das igrejas e ocupam os espaços públicos, as avenidas, as praças e os estádios de futebol, que 'viajam' pelo globo até acessar o seu destino final, o espectador" (Birman, 2003, p. 243).

Por fim, a igreja Universal se faz visível nos diferentes contextos nacionais como uma instituição cujo objetivo é "aliviar o sofrimento dos que sofrem”. Esta "instituição benevolente" doa bens distintos de acordo com o tipo de privação publicamente reconhecida em cada contexto nacional. Em Portugal, por exemplo, a atenção volta-se para as pessoas de terceira idade; no Brasil, em diferentes momentos enfatizou-se a pobreza do Nordeste, em 
especial, às populações que sofrem pela calamidade da seca; em Angola, as ações sociais estão conectadas com assistência de saúde e educação.

Em suma, o projeto pastoral aqui delineado autoregula-se não tanto pelo fato de cada indivíduo se reconhecer a si mesmo como um núcleo de agência empreendedora, mas sobretudo pela capacidade da elite da igreja de formular programas e doar benesses a formação dos indivíduos e das coletividades emergentes. Em outras palavras, no projeto pastoral de Edir Macedo os indivíduos submetem-se a determinações da elite da igreja, levando em conta valores de "solidariedade", "confiança" e "dependência".

\section{Notas}

1 Segundo o site oficial da igreja Universal no Brasil (<http://www.igrejauniversal.org.br>, consultado em 15.12.2009), a expansão internacional da IURD teve início em 1980, com a instalação de um espaço de cultos em Nova York. Porém, de acordo com o site da IURD em Portugal, a igreja se estabeleceu nos Estados Unidos em 1986. Freston (2001) aponta que a IURD começou a estabelecer, de fato, templos oficiais fora do Brasil em 1985, quando abriu uma igreja no Paraguai. Em 1989, além de Portugal, a IURD estabeleceu-se na Argentina e no Uruguai. A expansão tornou-se mais intensa a partir dos anos de 1990. Estima-se que, em 1995, havia 221 templos instalados no exterior; em 1998, este número aumentou para 500; e, em 2001, atingiu a marca de mil templos. Segundo o site da Universal no Brasil a igreja mantém hoje mais de 4.700 templos em 172 países. Pode-se dizer que, na maioria deles, sua implantação é simbólica, na medida em que mantém poucos templos e sua penetração é bastante restrita. Portugal, contudo, está entre os países em que a IURD alcançou uma expansão significativa, juntamente com Argentina, Venezuela, Reino Unido, Costa do Marfim, Moçambique, África do Sul e Estados Unidos (Oro et al., 2003). Portugal foi considerado uma porta de entrada estratégica para a Europa e para a "fila" dos migrantes portugueses espalhados por aquele continente (Aubrée, 2000; Mafra, 2002).

2 Esta pode ser identificada pela adesão à teologia da prosperidade ou à confissão positiva, porém não se reduz a isto. Originalmente, postula que os "verda- deiros cristãos devem desfrutar de uma excelente situação financeira, de saúde, etc. no tempo presente", invertendo, portanto, a expectativa tradicional da relação do cristão com o "mundo": de um excepcionalismo pelo sofrimento para um excepcionalismo pela abundância. No entanto, conforme demonstram Susan Harding (2000) e Simon Coleman (2000, 2006), várias outras dimensões da vida cristã passaram a demandar uma reelaboração teológica, a medida que os líderes evangélicos em diferentes contextos aderiram a versões dessa teologia. Um bom exemplo são as análises que Coleman (2006) realiza sobre a relação entre as palavras e as coisas no pentecostalismo carismático e sobre o processo de santificação dos líderes carismáticos.

3 As primeiras pesquisas, dissertações e teses desenvolvidas no Brasil sobre a igreja Universal chamaram atenção exatamente para este aspecto.A teologia da prosperidade, que até então só tinha penetração nas camadas médias e médias baixas urbanas, tornava-se atraente para alguns segmentos das camadas populares (Lima, 2008; Campos, 1997; Mariano, 1999).

4 Operamos com a distinção entre "individualização" referência a formação do indivíduo consolidado - e "individuação" - referência ao processo multivariado e não linear de formação do indivíduo moderno (Duarte, 2006; Dumont, 1985).

5 Clientelismo pode ser definido como um sistema político de relações hierárquicas entre atores, ou grupo de atores, que comandam uma distribuição desigual de recursos, envolvendo benefícios mútuos nas transações (Holanda, 1936; Leal, 1948, 1980; Carvalho, 1966, 1997; Diniz, 1982; Martins Filho, 1984, entre outros).

6 Forma de dominação pessoal e arbitrária que controla o acesso a recursos estratégicos.

7 A expressão "ideologia semiótica” é uma derivação do conceito de "ideologia linguística", que descreve a experiência dos povos com a linguagem de modo geral e, em particular, nos efeitos produtivos da consciência reflexiva dos falantes de uma comunidade de linguagem compartilhada (Schieffelin et al., 1998). Para entender a relação entre signos, pessoas e objetos, Webb Keanne propôs o conceito de "ideologia semiótica", que em suas palavras significa "o conjunto total de práticas envolvendo palavras e coisas no mesmo enquadramento" (2007, pp. 19-20). Mesmo não fazendo referência direta ao conceito, Susan Harding e Simon Coleman explicitam, em seus estudos sobre a teologia de Falwell e Ekman, processos sociais 
que poderiam ser adequadamente reconhecidos como "ideologias semióticas carismáticas".

8 Utilizamos a noção de modernidade cientes de sua construção como metanarrativa elaborada a partir de referências europeias que se sobrepõem às múltiplas modernidades locais (Englund e Leach, 2000).

9 Danièle Hervieu-Léger, no livro O peregrino e o convertido (1999), afirma que as religiōes no Ocidente, cuja validade institucional se fundamentara em torno do modelo paroquial territorial, encontram-se, atualmente, em completo remanejamento. Dois novos modelos de adesão religiosa, a do "convertido" (mais próxima do modelo paroquial) e a do "peregrino" (com uma institucionalização muito frouxa) surgiram. O paradoxo que estamos apontando é que a igreja Universal parece conviver perfeitamente bem com uma grande maioria de freqüentadores próximos ao modelo do peregrino, afirmando, nesta mesma medida, seu desenho institucional hierárquico e centralizado. Hervieu-Léger, por sua vez, supõe que haveria uma afinidade eletiva entre o "peregrino" e o modelo frouxo e descontínuo das "redes sociais".

10 Segundo o Censo 2000 (Instituto Brasileiro de Geografia e Estatística), a IURD tinha 2.101 .887 membros, o que significa que a igreja converteu $11,69 \%$ dos pentecostais do país em três décadas. Estima-se que, em 2000, os pentecostais fossem 17.975.249 ou $15,6 \%$ da população nacional.

11 Hoje em dia, a Universal mantém cerca de 110 lugares de culto em Portugal. Disponível em <www.iurd. pt>, consultado em 19.5.2010.

12 Em 1933 o Estado Novo foi estabelecido em Portugal, somente derrubado em 1974 , com a revolução de 25 de abril. Nesse período Antonio Salazar, líder popular e autoritário, conduziu um governo marcado pelo conservadorismo e nacionalismo.

13 Nas últimas décadas, Portugal tem registrado um ritmo de envelhecimento populacional superior a outros países europeus. Embora atualmente a população do país não seja a mais idosa no contexto europeu, é a que envelhece mais rapidamente (Barreto, 2000). Em 2001, 16,35\% da população de 10.356 .117 habitantes tinha mais de 65 anos (INE).

14 As campanhas são intervalos em que as práticas rituais cotidianas ganham força perante metas específicas, tendo uma temática como fio condutor.

$15 \mathrm{Na}$ contexto português, as práticas de luto são vividas com relativa intensidade.
16 Em Portugal, a igreja Universal mantém programação regular na TV Record Internacional e em diversas rádios locais espalhadas pelo país. Publica a Folha de Portugal, impresso semanal com tiragem de $50 \mathrm{mil}$ exemplares, e a revista Plenitude, com tiragem mensal de 40 mil exemplares.

17 A relação entre o Estado angolano e as igrejas modificou-se significativamente desde 1975, quando o governo assumiu uma postura antirreligiosa. Naquela época ocorreu perseguição aos religiosos católicos, protestantes, cristãos africanos, testemunhas de Jeová (Henderson, 1990) e provavelmente às religiōes tradicionais. Atualmente o MPLA busca apoio das instituiçõos religiosas para garantir a governabilidade. Ao lado da IURD, o Kimbanguismo destaca-se como "parceira" em diferentes ações governamentais (Sarro, Blanes e Viegas, 2008).

18 "Governadora de Luanda apela ao espírito da tolerância”. Disponível em <http://www.portalangop.co.ao/ motix/pt_pt/especiais/eleicoes/2008/7/35/Governadora-Luanda-apela-espirito-tolerancia, a0f877d4-414b-4835-a2ae-6f5af02529ac.html>, consultado em 20.5.2010.

19 Criada em 1994 sob o lema "Caridade não tem religião”, a Associação Beneficente Cristã (ABC) é responsável pelas principais atividades e projetos assistencialistas desenvolvidos pela Igreja Universal no Brasil e no exterior.

\section{BIBLIOGRAFIA}

ALMEIDA, Ronaldo de. (2009), A Igreja Universal do Reino de Deus e seus demônios. São Paulo, Terceiro Nome.

AUBRÉE, Marion. (2000), "La diffusion du pentecôtisme brésilien en France et en Europe: le cas de l'IURD", in C. Lerat e B. Rigal-Cellard (eds.), Les mutations transatlantiques des religions, Bordeaux, PUB.

BARRETO, António. (2000), A situação social em Portugal, 1960-1995. Lisboa, Imprensa de Ciências Sociais.

BIALECKI, Jon; HAYNES, Naomi \& ROBBINS, Joel. (2008), "The anthropology of Christianity". Religion Compass, 2 (6): 1139-1158.

BIRMAN, Patrícia. (2003), "Imagens religiosas e projetos para o futuro", in P. Birman (ed.), Religião e espaço público, São Paulo, Attar. 
BITTENCOURT, Marcelo. (1996), As linhas que formam o "EME": um estudo sobre a criação do Movimento Popular de Libertação de Angola. São Paulo, dissertação de mestrado, USP. . (2002), Estamos juntos: o MPLA e a luta anticolonial (1961-1974). Rio de Janeiro, tese de doutorado, Universidade Federal Fluminense.

BURITY, Joanildo \& MACHADO, Maria das Dores (eds.). (2005), Os votos de Deus: evangélicos, politica e eleiçôes no Brasil. Recife, Fundação Joaquim Nabuco.

CAMPOS, Leonildo. (1997), Teatro, templo e mercado. Petrópolis, Vozes.

CANNELL, Fenella (ed.). (2006), Anthropology of christianity. Durham, Duke University Press.

COLEMAN, Simon. (2006), "Materializing the self: words and gifts in the construction of the charismatic protestant identity", in F. Cannell (ed.), The anthropology of christianity, Durham, Duke University Press.

. (2000), The globalization of charismatic christianity: spreading the gospel of prosperity. Cambridge, Cambridge University Press.

CARVALHO, José Murilo. (1966), "Barbacena: a família, a política e uma hipótese". Revista Brasileira de Estudos Políticos, 20: 153-194.

. (1997), "Mandonismo, coronelismo, clientelismo: uma discussão conceitual”. $D a$ dos, 40 (2): 229-250.

CORTEN, Andre. (2003), "A igreja Universal na África do Sul”, in A. P. Oro, A. Corten e J. Dozon (eds.), A igreja Universal do Reino de Deus: os novos conquistadores da fé, São Paulo, Paulinas.

DILLEY, Roy Martin. (2010), "Reflections on knowledge practices and the problem of ignorance". Journal of the Royal Anthropological Institute, 16 (Supplement S): 176-192.

DINIZ, Eli. (1982), Voto e máquina política: patronagem e clientelismo no Rio de Janeiro. Rio de Janeiro, Paz e Terra.

DUARTE, Luiz Fernando Dias. (2006), "Ethos privado e modernidade: o desafio das religiōes entre indivíduo, família e congregação", in F. Duarte et al. (orgs.), Familia e religião, Rio de Janeiro, Contracapa.
DUMONT, Louis. (1985), O individualismo: uma perspectiva antropológica da ideologia moderna. Rio de Janeiro, Rocco.

ENGLUND, Harri \& LEACH, James. (2000), "Ethnography and the meta-narratives of modernity". Curretn Anthropology, 41 (2): 225-248.

FONSECA, Alexandre. (2003), "Fé na tela: características e ênfases de duas estratégias evangélicas na televisão". Religião \& Sociedade, 23 (2): 33-52.

FERRARI, Odêmio. (2007), Bispo S/A. A igreja Universal do Reino de Deus e o exercício de poder. São Paulo, Ave Maria.

FRESTON, Paul. (1993), Protestantes e politica no Brasil: da Constituinte ao impeachment. Campinas, tese de doutorado, Unicamp.

. (2001), "The transnationalisation of

Brazilian pentecostalism: the Universal Church of the Kingdom of God", in, André Corten e Ruth Marshall-Fratani (orgs.), Betweeen Babel and Pentecostalism: transnational pentecostalism in Africa and Latin America, Londres, Hurst \& Company.

. (2005), "The Universal Church of the kingdom of god: a Brazilian church finds success in Southern Africa". Journal of Religion in Africa, 35 (1): 33-65.

(ED.). (2008), Evangelical christianity and democracy in Latin America. Oxford, Oxford University Press.

GIUMBELLI, Emerson. (2002), O fim da religiāo: dilemas da liberdade religiosa no Brasil e na França. São Paulo, Attar.

GOMES, Edlaine. (2004), A era das catedrais. Rio de Janeiro, tese de doutorado, Universidade do Estado do Rio de Janeiro.

GRAHAM, Richard. (1997), Clientelismo e politica no Brasil do século XIX. Rio de Janeiro, Editora da UFRJ.

HARDING, Susan. (1991), "Representing fundamentalism: the problem of the repugnant cultural other". Social Research, 58 (2): 373-393. . (2000), The book of Jerry Falwell: fundamentalist language and politics. Princeton, Princeton University Press.

HEFNER, Robert W. (ed.). (1993), Conversion to Christianity: historical and anthropological 
perspectives on a great transformation. Berkeley, University of California Press.

HENDERSON, Lawrence. (1990), A igreja em Angola: um rio com várias correntes. Lisboa, Além Mar.

HERVIEU-LÉGER, Danièle. (2008), O peregrino e o convertido: a religião em movimento. Petrópolis, Vozes.

HODGES, Tony. (2002), Angola: do afro-estalinismo ao capitalismo selvagem. S. João do Estorial, Principia.

HOLANDA, Sergio Buarque. (1936), Raízes do Brasil. Rio de Janeiro, José Olympio.

KAMP, Linda Van de. \& DIJK, Rijk van. (2010), "Pentecostals moving South-South: Brazilian and Ghanaian transnationalism in Southern Africa”, in A. Adogame e J. Spickard (eds.), Religion crossing boundaries: transnational $d y$ namics in Africa and the new African diasporic religions, Leiden, Brill.

KEANE, Webb. (2007), Christian moderns: freedom and fetish in the mission encounter. Berkeley, University of California Press.

KRAMER, Eric. (2001), Possessing faith: commodification, religious subjectivity, and collectivity in a Brazilian neo-pentecostal church. Chicago, tese de doutorado, University of Chicago.

LEAL, Victor Nunes. (1948), Coronelismo, enxada e voto. Rio de Janeiro, Forense.

. 1980), "O coronelismo e o coronelismo de cada um”. Dados, 23 (1): 11-14.

LIMA, Diana. (2008), "Prosperidade na década de 1990: etnografia do compromisso de trabalho entre Deus e o fiel da igreja Universal do Reino de Deus". Dados, 51: 7-36.

MACEDO, Edir \& OLIVEIRA, Carlos. (2008), Plano de poder: Deus, os cristãos e a política. Rio de Janeiro, Thomas Nelson Brasil.

MACHADO, Maria das Dores. (2003), "Igreja Universal: uma organização providencia”, in A. P. Oro, A. Corten e J. Dozon (eds.), A igreja Universal do Reino de Deus: os novos conquistadores da fé, São Paulo, Paulinas.

MAFRA, Clara. (2002), Na posse da palavra: religião, conversão e liberdade pessoal em dois contextos nacionais. Lisboa, Imprensa de Ciências Sociais.
MAFRA, Clara \& SWATOWISKI, Claudia. (2008), "O balão e a catedral: trabalho, lazer e religião na paisagem carioca”. Anthropológicas, 19 (1): 141-167.

MALHEIROS, Jorge. (1996), Imigrantes na regiāo de Lisboa: os anos da mudança. Lisboa, Colibri.

MARIANO, Ricardo. (1999), Neopentecostais: sociologia do novo pentecostalismo no Brasil. São Paulo, Loyola.

MARIZ, Cecília. (2009), "Missão religiosa e migração: 'novas comunidades' e igrejas pentecostais brasileiras no exterior”. Análise Social, XLIV (1): 161-187.

MARTINS FILHO, Amilcar. (1984), "Clientelismo e representação em Minas Gerais durante a Primeira República: uma crítica a Paul Cammack". Dados, 27 (2): 175-197.

ONG, Aihwa. (2005), "Clash of civilizations or asian liberalism? Anthropology of the State and the citizenship", in H. Moore (ed.), Antropological theory today, Cambridge, Polity Press.

ORO, Ari Pedro; CORTEN, André \& DOZON, Jean-Pierre (eds.). (2003), A igreja Universal do Reino de Deus: os novos conquistadores da fé. São Paulo, Paulinas.

PEREIRA, Luena. (2005), "Diversidade linguística e identidade nacional: investigando afirmações alternativas de nacionalidade em Angola em cultos religiosos", in T. Cruz; Silva, M. G. Araújo e C. Cardoso (orgs.), Lusofonia em Africa: história, democracia e integração africana. Dakar, Codesria.

REINHARDT, Bruno. (2007), Espelho ante espelho: a troca e a guerra entre o neopentecostalismo $e$ os cultos afro-brasileiros em Salvador. São Paulo, Attar.

ROBBINS, Joel. 2004. "The Globalization of Pentecostal and Charismatic Christianity". Annual Review of Anthropology, 33: 117-143.

. (2006), "Anthropology and theology: an awkward relationship?". Anthropological Quarterly, 79 (2): 285-294.

. (2008), "Sobre alteridade e o sagrado em uma época de globalização: o "trans" em "transnacional” é o mesmo do "trans" de “transcendente”?". Mana, 14 (1): 119-140. 
SARRÓ, Ramon \& BLANES, Ruy. (2009), "Prophetic diasporas: moving religion across the lusophone Atlantic". African Diaspora, 2 (1): 52-72.

SARRÓ, Ramon; BLANES, Ruy \& VIEGAS, Fátima. (2008), "La guerre dans la paix: ethnicité et angolanité dans l'Église kimbanguiste de Luanda”. Politique Africaine, 110: 84-101.

SCHIEFFELIN, Bambi; WOOLARD, Kathryn \& KROSKY, Paul (eds.). (1998), Language ideologies: practice and theory. Nova York/Oxford, Oxford University Press.

SILVA, Tereza Cruz e; ARAUJO, Manuel G. \& CARDOSO, Carlos (eds.). (2005), Lusofonia em Africa: historia, democracia e integração africana, Dakar, Codesria.

SWATOWISKI, Claudia. (2009), "Dinâmicas espaciais em Macaé: lugares públicos e amientes religiosos”, in C. Mafra e R. Almeida (eds.), Religióes e cidades, Rio de Janeiro/São Paulo, Terceiro Nome.

- (2010), Novos cristãos em Lisboa: reconhecendo estigmas, negociando esterétipos. Rio de Janeiro, tese de doutorado, Universidade do Estado do Rio de Janeiro.

TAYLOR, Charles. (1989), The sources of the self. Cambridge, Cambridge University Press.

TAVOLARO, Douglas. (2007), O bispo: a historia revelada de Edir Macedo. São Paulo, Larousse.

VIEGAS, Fátima. (1999), Angola e as religióes. Luanda, s. e. 


\section{O PROJETO PASTORAL DE EDIR MACEDO: UMA IGREJA BENEVOLENTE PARA INDIVÍDUOS AMBICIOSOS?}

\author{
Clara Mafra, Claudia Swatowiski e \\ Camila Sampaio
}

Palavras-chave: Cristianismo; Teologia da prosperidade; Religiosidade transnacional; Secularismo.

Neste artigo, discute-se a singularidade do projeto pastoral de Edir Macedo, líder da Igreja Universal do Reino de Deus. Esse projeto tem em vista um modelo de regulação social altamente sedutor em sociedades neoliberais com larga presença de economias informais. De um lado, o modelo supóe o desenvolvimento de uma instituição que divulga um discurso moral que refuta o individualismo "narcisista" e "corrupto", e oferece, como alternativa, rituais que promovem o empreendedor sacrificial, disciplinado e voltado para a família. De outro lado, supóe que a elite clerical ofereça acesso a "bens sociais" para a grande maioria dos freqüentadores. Nesse sentido, argumentam as autoras, a natureza autoritária da igreja é sustentada por uma expectativa de tutela por parte das populaçóes. Apoiadas em dados coletados em Brasil, Portugal e Angola, as autoras ponderam sobre a relação entre ideal de responsabilidade social, cultura política regional e manutenção de um poder pastoral hierárquico e autoritário como o da Igreja Universal.

\section{THE PASTORAL PROJECT OF EDIR MACEDO: A CARING CHURCH FOR ASPIRING INDIVIDUALS}

\section{Clara Mafra, Claudia Swatowiski and Camila Sampaio}

Keywords: Christianity; Theology of prosperity; Secularism; Transnational religiosity.

This article discusses the particularity of the theological project of Edir Macedo, leader of The Universal Church of the Kingdom of God. The authors propose that this group operates according to an institutional and social regulatory model that is highly seductive in neoliberal societies with large informal economies. The church presents a moral discourse that refutes 'narcissistic' and 'corrupt individualism,' and offers as an alternative rituals that promote sacrificial entrepreneurs who are disciplined and dedicated to family. It is also expected that the elite of the Universal Church provides access to 'social goods' for the vast number of churchgoers. In these ways the authoritarian nature of the church is supported through an expectative of tutelage. Drawing on data from Brazil, Portugal, and Angola, the authors also discuss the relationship between an ideal of social responsibility, the regional political cultures and the maintenance of hierarchical and authoritarian pastoral power at the Universal Church.

\section{LE PROJET PASTORAL DE EDIR MACEDO: UNE ÉGLISE BÉNÉVOLENTE POUR DES INDIVIDUS AMBITIEUX?}

\section{Clara Mafra, Claudia Swatowiski and Camila Sampaio}

Mots-clés: Christianisme; Théologie de la prospérité; Religiosité transnationale; Sécularisme.

Cet article aborde la singularité du projet pastoral de Edir Macedo, chef de l'Igreja Universal do Reino de Deus (Église Universelle du Royaume de Dieu). Ce projet suit le modèle de régulation sociale hautement séducteur dans les sociétés néolibérales avec une large présence d'économies informelles. D'une part, le modèle suppose le développement d'une institution qui divulgue un discours moral qui rejette l'individualisme "narcissiste" et "corrompu", et offre comme alternative des rituels qui font la promotion de l'entrepreneur sacrificiel, discipliné et dédié à la famille. D’autre part, il suppose que l'élite cléricale offre l'accès à des "biens sociaux" pour une grande majorité des fidèles. Ainsi, les auteurs de l'article défendent que la nature autoritaire de l'église est soutenue par une espérance de tutelle de la part des populations. Ayant pour base des données collectées au Brésil, au Portugal et en Angola, les auteurs pondèrent sur le rapport entre l'idéal de responsabilité sociale, de culture politique régionale et de maintien d'un pouvoir pastoral hiérarchique et autoritaire comme celui de l'Igreja Universal. 